\title{
Remediation effects on N170 and P300 in children with developmental dyslexia
}

\author{
Mélanie Jucla ${ }^{\mathrm{a}, \mathrm{b}, 1, *}$, Rodolphe Nenert ${ }^{\mathrm{a}, \mathrm{c}, 1}$, Yves Chaix ${ }^{\mathrm{a}, \mathrm{c}, \mathrm{d}}$ and Jean-François Demonet ${ }^{\mathrm{a}, \mathrm{c}, \mathrm{d}}$ \\ anserm, Imagerie cérébrale et handicaps neurologiques UMR 825, Toulouse, France \\ ${ }^{\mathrm{b}}$ E.A Octogone. Laboratoire Jacques-Lordat, E.A 4156, Université Toulouse II Le Mirail, Toulouse, France \\ ${ }^{\mathrm{c}}$ Universite de Toulouse; UPS; Imagerie cérébrale et handicaps neurologiques UMR 825; CHU Purpan, Toulouse \\ Cedex 9, France \\ ${ }^{\mathrm{d}}$ Centre Hospitalier Universitaire de Toulouse, Pole Neurosciences, CHU Purpan, Toulouse Cedex 9, France
}

\begin{abstract}
This study aimed at investigating the ERP correlates (N170 and P300 components) of a multimodal training program focused in dyslexia. ERPs were obtained from 32 electrodes in 24 French children with developmental dyslexia (mean age 10 years 7 months) during a visual lexical decision task. All the children received two intensive two-month evidence-based training programs: one based on phonemic awareness and the other on visual and orthographic processing in a cross-over design. Ten control children matched on chronological age were also tested. We showed dissociation between N170, P300 and behavioral improvement. In the dyslexic group, P300 amplitude decreased for non-words and words as the latter yielded performance improvement. In the control group, the same effect was observed for pseudo-words. At the same time, the opposite pattern occurred for the N170 latency, which was shortened for pseudo-words and pseudo-homophones in the dyslexic group and for words in the typically achieving children. We argue that training might modulate cortical activity in dyslexic children in a visual word recognition task. Considering the well-known implication of P300 in attentional processes, our results reflect the strong link between reading skill improvement after remediation and visual attentional process maturation.
\end{abstract}

Keywords: Developmental dyslexia, remediation, children, phonological, visual attention, ERPs

\section{Introduction}

Dyslexia, or reading difficulty, is one of the most common problems that severely affect academic performance. It is revealed as a difficulty in learning to read despite conventional teaching, without being the direct result of any intellectual disadvantage or unfavorable environmental influence [2]. It is still not precisely known what factors prevent normal acquisition of reading abilities, as reading is a complex phenomenon. In the last 20 years, the most convergent evidence has arisen from the phonological deficit hypothesis, according to which the difficulties suffered by dyslexic children in identifying words in a text are due to deficiencies in their ability to segment the flow

\footnotetext{
${ }^{1}$ These authors contributed equally to this work.

* Corresponding author: Mélanie Jucla, Laboratoire OctogoneLordat, Université de Toulouse le Mirail, Pavillon de la recherche, 5, allées Antonio Machado, F-31058 Toulouse Cedex, France. Tel.: +33561502469.
}

of speech into its sound components, also known as phonological awareness [33,47-50]. However, alternative explanations have been suggested, implicating visual attention [15]. Recently, Valdois and collaborators [4] found a link between visuo-attentional span and reading process. The authors suggest that phonological and visuo-attentional skills are implied in reading efficiency, considering that their alteration results in poor performance in tasks that permit developmental dyslexia to be characterized.

Several remediation programs have been suggested for dyslexia, each of them focusing on one 'core' deficit. Several studies have shown significant improvement in reading skills using remediation programs based on phonological processing only [18] (see Beaton for a review [2]) or instruction combining phonic coding and literacy skills [25,54]. Magnan and collaborators used audiovisual software to train dyslexic children in grapheme-phoneme correspondence rules [26,27]. They found significant improvement in word recognition after training. However, Alexander and Slinger- 
Constant underlined the fact that, despite improvements observed after training, a substantial number of dyslexic children resist treatment, whatever the remediation modality [1].

The event-related potential (ERP) technique has allowed researchers to decompose the cognitive process of word reading into temporal phases. With regard to our interest in developmental impairment, two crucial components have been identified:

The first peak around $170 \mathrm{~ms}$ after the stimulus onset (N170 hereafter) is thought to reflect the first cognitive orthographic process with a source in occipito-temporal regions $[22,37]$. Some authors infer that this component reflects the first letter-specific treatment compared to that of any other symbol [41]. In addition, its amplitude is larger after word or even pseudo-word (i.e. pronounceable meaningless letter sequence) than nonword (i.e. illegal letter sequence as for instance string of consonants) presentation, suggesting a pre-lexical component $[3,8,28,30,32,36]$. However, this component has been found to be modulated by word lexical frequency $[45,46]$. These latter works suggest that N170 may also reflect lexical access in single word reading. This component has been found to differ in dyslexic subjects compared to controls in several studies, generally revealing a higher latency and lower amplitude in dyslexic subjects $[19,41,42,51,52]$. N170 amplitude increase during reading learning seems to characterize reading level. In a longitudinal study, Maurer et al. showed that N170 amplitude increased with learning and that this effect was reduced in children with reading impairment [29].

The second component is a positive wave that occurs around $300 \mathrm{~ms}$ after stimulus presentation (P300 hereafter) and is known to reflect the amount of attentional resources involved in a task [21,57]. However, considering written word processing, it has been found that word recognition elicits a higher P300 [40] and a lack of P300 when subjects are stimulated with pseudohomophones or words with internal case changes [44]. Moreover, Duncan et al. observed P300 anomalies in adults with dyslexia who had also suffered from attentional disorder during childhood [12]. Thus, considering that attentional disorders are frequently observed in dyslexic subjects, it is difficult to resolve whether P300 anomalies are only due to dyslexia or associated with attention disorders [53].

Few studies address the question of the consequence of remediation on the temporal course of written word processing in dyslexia. Recently, Santos et al. studied the effects of a training program based on both phonemic awareness and grapheme-phoneme correspondence exercises $[9,17,18]$ on auditory language semantic integration [43]. Before training, ERPs (between 200 and $700 \mathrm{~ms}$ ) were modulated by incongruity in the typically achieving children only. After training the same effect was observed in the dyslexic group.

The aim of the present paper is to study the ERP correlates of a multimodal evidence-based remediation program that focused on two major deficits in dyslexia, phonological and visual attentional. With this is mind, we analyzed two crucial components, the N170 and P300 in a lexical decision task using a typical Oddball paradigm in dyslexic children that followed our program compared to typically achieving children as a baseline. We hypothesized that control subjects should show larger N170 and P300 with shorter latencies than dyslexic children and that the latter should present a more typical pattern of activity after remediation.

\section{Methods}

\subsection{Participants}

24 French-native-speaker dyslexic children from 9 to 11 years old ( 9 girls and 15 boys) were recruited. All subjects had an IQ $>80$ as tested with WISC-III [56] and a reading delay of at least 18 months as tested by a standardized French reading test (L'Alouette [24]). All subjects satisfied developmental dyslexia diagnosis criteria according to ICD-10 classification (WHO, 1993). They had no specific attentional disorder as tested by the D2 test [5], no oral language delay as tested by L2MA [6] and TCG [10] and no comprehension disorder as tested by ECOSSE [23].

In addition, 11 French-native-speaker control children from 9 to 11 years old (4 girls and 7 boys) were also recruited. They had no IQ deficit or reading level delay, as tested by WISC-III [56] and the "Alouette" tests [24] respectively. Nor chronological age neither IQ differed between the control group and the dyslexic group (resp. $p=0.15$ and $p=0.14$ ).

\subsection{Remediation program}

Training sessions were implemented six days a week and lasted from ten to twenty minutes each day. Children were assisted by their parents at home or by their speech therapist, who switched from the usual therapy to these programs. Before each training period, specific material (stimuli and exercises, audio CD and notebooks) was delivered to the parents and detailed explanations and examples were provided (written directions 
were also given). Adults were asked to provide feedback to the child, especially in case of erroneous responses. They were taught how to use the material and what instructions and feedback to give the child during a one-hour training session. After each training period, exercise notebooks were collected and reviewed, and a debriefing with the parents and the speech therapist was held in order to check the reliability of the interventions.

Data from one child were discarded because of lack of precision and compliance in the training program (this child was not included in the sample described above).

\subsubsection{The phonological training}

This training was derived from that used in Habib et al. [18]. Stimuli were presented through headphones from an audio CD. The adult had to give the instructions and take note of the child's answers in an exercise book. There were 6 exercises per day. The typical pattern of exercises was different between weeks 1, 3, 5 and weeks 2, 4, 6 .

Exercises proposed during weeks 1, 3 and 5 were as follows:

The first three exercises contained triplets of words the child had to compare phonologically to disclose similarity between 2 of the 3 stimuli, either in the rhyme, the onset, or the middle part of words (for example, "which words rhyme among the triplet "boat", "coat", "bowl"?"). The other exercises consisted of syllable counting, phoneme detection ("How many times can you hear the sound /s/ in 'sausage'?") and finally, word repetition.

Exercises proposed during weeks 2, 4 and 6 were as follows:

The items were pseudo-words during weeks 2 and 6 , and words during week 4 . In the first two exercises, the children were asked to find the odd word among three pseudo-words or words. The oddity was based on the rhyme (exercise 1) or the onset (exercise 2). In the third exercise, the children had to find a target phoneme in one of the three pseudo-words or words. Then a phoneme counting task was proposed followed by spoonerisms (based on words). Finally the child had to repeat pseudo-words or words.

\subsubsection{The visual training}

The visual training was split into two different parts.

The first 3 weeks consisted of non-verbal visual attentional training while the second 3 weeks consisted in a shift of visual attention and perception exercises from the non-verbal to the verbal domain. The first, non-verbal phase was meant to provide initial training so that children could become familiar with heavy-duty exercises on visual/graphic stimuli. The second phase also involved visual stimuli but they consisted of orthographic material.

The first-phase, non-verbal exercises were derived from various tests and rehabilitation sets used in speech therapy for dyslexia remediation. The exercises mainly focused on:

- Space organization: path finding through a mazelike design, drawing a path by following arrows or between an arrangement of points identical to that represented on a model,

- Visual attention: identifying superposed geometrical forms, matching a drawing to sample, coding, matching nonsense figures by sticking them on the model, superposing geometrical figures with their matching model drawn on a transparency sheet.

- Logic: matrix completion tasks.

Responses were checked and corrected by the parents or the speech therapist.

The second 3-week period was a specific visual orthographic training that had been built up for a previous study in our laboratory with the cooperation of speech therapists (see typical examples of exercises in Appendix C). The goal of this part was to enhance access to orthographic knowledge and lead subjects to work out and visualize word orthography mentally. The exercises mainly focused on:

- Shape of letters and words: for each letter in an orally presented word, saying if it went up (e.g. "d"), down (e.g. "p") or in the middle (e.g. "e"); identifying if a "shadow envelope" could hide a target word.

- Searching for a word or a letter: identifying a word embedded in a string of letters; chunking a text presented without spaces; linking spread letters according to a model word; letter cancellation task.

- Orthographic knowledge: spelling out or counting the letters in an orally presented word and writing it down; naming the letters situated just before and after a target letter in an orally presented word.

- Word comparisons: similarity judgment task in word pairs; choosing which of four choices was identical to the model; finding the missing letter in a word; identifying the longest word.

- Reading a word presented in an unusual manner: vertically; around a circle.

- Converting a non-word presented in upper case letters into lower case or the contrary. 


\subsection{Procedures}

In order to avoid any order effect in remediation, 12 dyslexic children first followed the phonological remediation then the visual remediation. The other 12 dyslexic children started with the visual remediation then followed the phonological remediation. Children were included in one of the two groups by alternation. All children underwent EEG recording twice: before the training (Session 1) and after training (Session 2, 19 weeks after session 1 ).

During each EEG session, ERPs were obtained for each child, who had to complete a visual lexical decision task. This task involved 128 items that were distributed over 4 conditions in an Oddball paradigm: 32 words, 32 pseudo-words (pronounceable meaningless sequences), 32 pseudo-homophones (same phonology as, different spelling than a real word) and 32 nonwords (unpronounceable letter sequences). This particular stimuli distribution was made to elicit maximum subject attention over word stimuli. Three lists of 128 items were created in order to have different stimuli in each EEG session; these lists were balanced for lexical frequency, number of letters, and syllable structure. List order was counterbalanced between subjects.

Subjects were comfortably seated in front of a screen in a quiet room. During the task, a centrally located fixation cross stimulus first appeared for $500 \mathrm{~ms}$, then one item appeared for $250 \mathrm{~ms}$, followed by a fixation cross again. Inter-stimulus interval varied between 1700 and $2000 \mathrm{~ms}$. The subjects were explicitly asked to indicate whether the sequence presented was a French word by pressing one of two designated keys using both hands. The use of the right versus the left index to designate real words was alternated between subjects.

\subsection{ERP acquisition}

The electroencephalogram (EEG) was recorded with a $0.1-100 \mathrm{~Hz}$ filter and a $500 \mathrm{~Hz}$ sampling rate using Neuroscan 4.2 software and a 32-electrode Neuroscan device (Ag-AgCl electrodes). Impedances for all electrodes were kept below 5 kohms. The vertex electrode was used as the recording reference. Eye-movements were monitored with two electrodes: one placed above the left eye and one placed on the right temple.

The epochs contaminated by eye-movements or artifacts of non-biological origin producing voltages larger than $+/-125 \mu \mathrm{V}$ peak-to-peak were omitted from averaging.
The ERPs were digitally filtered with a low-pass filter of $30 \mathrm{~Hz}$ (12dB/Octave, zerophase-type filter) and a high-pass filter of $0.5 \mathrm{~Hz}(12 \mathrm{~dB} /$ Octave, zerophasetype filter).

The analysis epoch began $100 \mathrm{~ms}$ before and terminated $1200 \mathrm{~ms}$ after stimulus onset.

A baseline correction was applied from $-100 \mathrm{~ms}$ to $0 \mathrm{~ms}$. Average reference was applied to all ERPs.

\subsection{Analyses}

\subsubsection{Behavioral statistics}

Data from one dyslexic child was discarded due to a problem in response recording. An ANOVA with repeated measures was carried out on number of correct answers (accuracy rate) with Session (session 1 and 2) X Condition (words, pseudo-words, pseudohomophones and non-words) as intra-individual factors and group (experimental group and control group) as inter-individual factor.

\subsubsection{ERP statistics}

In a first step, we conducted an automatic peak research on defined time windows (using the Global Field Power (GFP) of 32 electrodes on average waves in the control group [35]): [150-250] ms for N170 and [250400] ms for P300.

Data from two dyslexic children were discarded due to a problem in signal recording. Peak mean amplitudes and latencies were analyzed using ANOVA with repeated measures on the electrodes that showed the highest sensitivity: P7, P8, PO9, PO10, O1 and O2. Session (before/after training), condition (non-word, pseudoword, homophone and word), hemisphere (right/left) and electrode were considered as intra-individual factors. Group (dyslexic versus control) was considered as an inter-individual factor. To clarify the results described below, we have chosen not to report main effect or interactions involving the 'electrode' factor.

\section{Results}

\subsection{Behavioral results}

Raw scores (and SD) are presented in Table 1. Analysis on the accuracy rate revealed a significant group effect $(\mathrm{F}(1,32)=5.65, p=0.023)$, dyslexic children being less efficient that control children. Both groups showed a significant improvement between two sessions $(\mathrm{F}(1,32)=4.71, p=0.037)$. Performance was 
Table 1

Results obtained (\% of accuracy) in different conditions of the visual lexical decision task in dyslexic and control group. S1 stands for session 1 (resp. S2 for session 2). Standard deviation is in brackets

\begin{tabular}{|c|c|c|c|c|c|c|c|c|}
\hline \multirow[t]{2}{*}{ Group } & \multicolumn{2}{|c|}{ Pseudo-homophones } & \multicolumn{2}{|c|}{ Non-words } & \multicolumn{2}{|c|}{ Words } & \multicolumn{2}{|c|}{ Pseudo-words } \\
\hline & S1 & $\mathrm{S} 2$ & S1 & S2 & S1 & S2 & $\mathrm{S} 1$ & S2 \\
\hline Dyslexic & $44.7(22.2)$ & $48.0(21.1)$ & $68.0(26.5)$ & $69.5(26.3)$ & $55.3(24.6)$ & $63.6(20.2)$ & $51.4(23.7)$ & $55.7(19.1)$ \\
\hline Control & $56.5(24.0)$ & $60.1(24.5)$ & $82.1(21.0)$ & $84.6(20.0)$ & $75.3(17.9)$ & $70.3(21.1)$ & $65.2(21.8)$ & $80.8(18.2)$ \\
\hline
\end{tabular}

affected by condition $(\mathrm{F}(3,96)=15.72, p<0.001)$. A post-hoc Tukey test showed that the non-word condition was the easiest (significant difference between nonwords and words $-p<0.05-$ and both types of pseudowords $-p<0.001$ ) and pseudo-homophones were the hardest (difference between pseudo-homophones and words, non-words $-p<0.001$ - and pseudowords $p<0.05)$. Session $\mathrm{x}$ Group or Condition x Group interactions were not significant whereas a Session $x$ Condition $x$ Group interaction was significant $(\mathrm{F}(3,96)=$ 2.76, $p=0.046$ ). A post-Hoc Tukey test showed that, in the control group, in session 1, pseudo-homophones were significantly less well identified than words $(p<$ $0.05)$. This difference disappeared in session 2 . In the dyslexic group, words were significantly less well identified than non-words in session $1(p<0.05)$. This difference disappeared in session 2 due to an improvement in word identification.

\section{ERP results}

Curves are depicted in Fig. 1.

N170: Peak latency analysis showed that only the Session $x$ Group $x$ Condition interaction was significant $(\mathrm{F}(3,93)=3.97, p=0.01)$. According to the post hoc analysis (Fisher LSD test), latency was found to be smaller in session 2 compared to session 1 for nonwords in the control group $(p<0.005)$ and for pseudowords in the dyslexic group $(p=0.06)$.

Peak mean amplitude analysis also showed that only the Session $x$ Group $x$ Condition interaction was significant $(\mathrm{F}(3,93)=2.87, p<0.05)$, the amplitude being smaller in dyslexic children for pseudo-words and pseudo-homophones after training (Tukey test; resp. $p<0.001$ and $p<0.005$ ).

P300: Peak latency analysis showed that only the Session $\mathrm{x}$ Group interaction was significant $(\mathrm{F}(1,31)=$ 4.2, $p<0.05)$, control children having smaller latency in session 2 (Fisher LSD test; $p=0.06$ ).

Peak mean amplitude analysis showed a Condition main effect as a Condition $\mathrm{x}$ Hemisphere significant interaction (respectively $\mathrm{F}(3,93)=4.6, p<0.005$ and $\mathrm{F}(3,93)=5.23, p<0.005)$. The mean amplitude was higher for words compared to both types of pseudowords (Tukey test; $p<0.001)$ and non-words $(p<$ $0.05)$ in the left hemisphere only. Session X Condition $\mathrm{X}$ Group interaction was - gnificant $(\mathrm{F}(3,93)=4.08$, $p<0.01$ ), showing an amplitude decrease in the control group for both types of pseudo-words $(p<0.005)$ and in the dyslexic group for words and non-words ( $p<$ 0.001 ) in session 2 compared to session 1 .

\section{Discussion}

In this study we have investigated the neural correlates of reading improvement after intervention in developmental dyslexia. We analyzed dyslexic children's ERPs elicited by a lexical decision task before and after a four-month phonological and visual orthographic training program. We compared their data to those of typically achieving children as a baseline before and after the period of four months. We were interested in the main effects of group, task condition, session and interactions between these parameters.

If we first look at the main group effects, not surprisingly, dyslexic children were found to have poorer behavioral performance on the visual lexical decision task. This supports the orthographic encoding deficit in dyslexia [11].

We also highlighted main condition effects in behavioral and electrophysiological data in both groups. First, considering accuracy scores, the non-word condition was easier to address than the pseudo words, pseudo-homophones and even words. According to the DRC reading model, processing an unpronounceable letter sequence and deciding it is not a word is faster because one does not have to processes more than orthotactic information [7]. For pseudo-words, the subject has to activate a phonological content and then may check whether it activates semantic information. Furthermore, the latter could be responsible for the specific difficulty in addressing the pseudo-homophones. Processing a homophone yields a mismatch between the current orthographic visual input and the orthographic information that is sent back after the corresponding semantic contents have been activated. While this ef- 


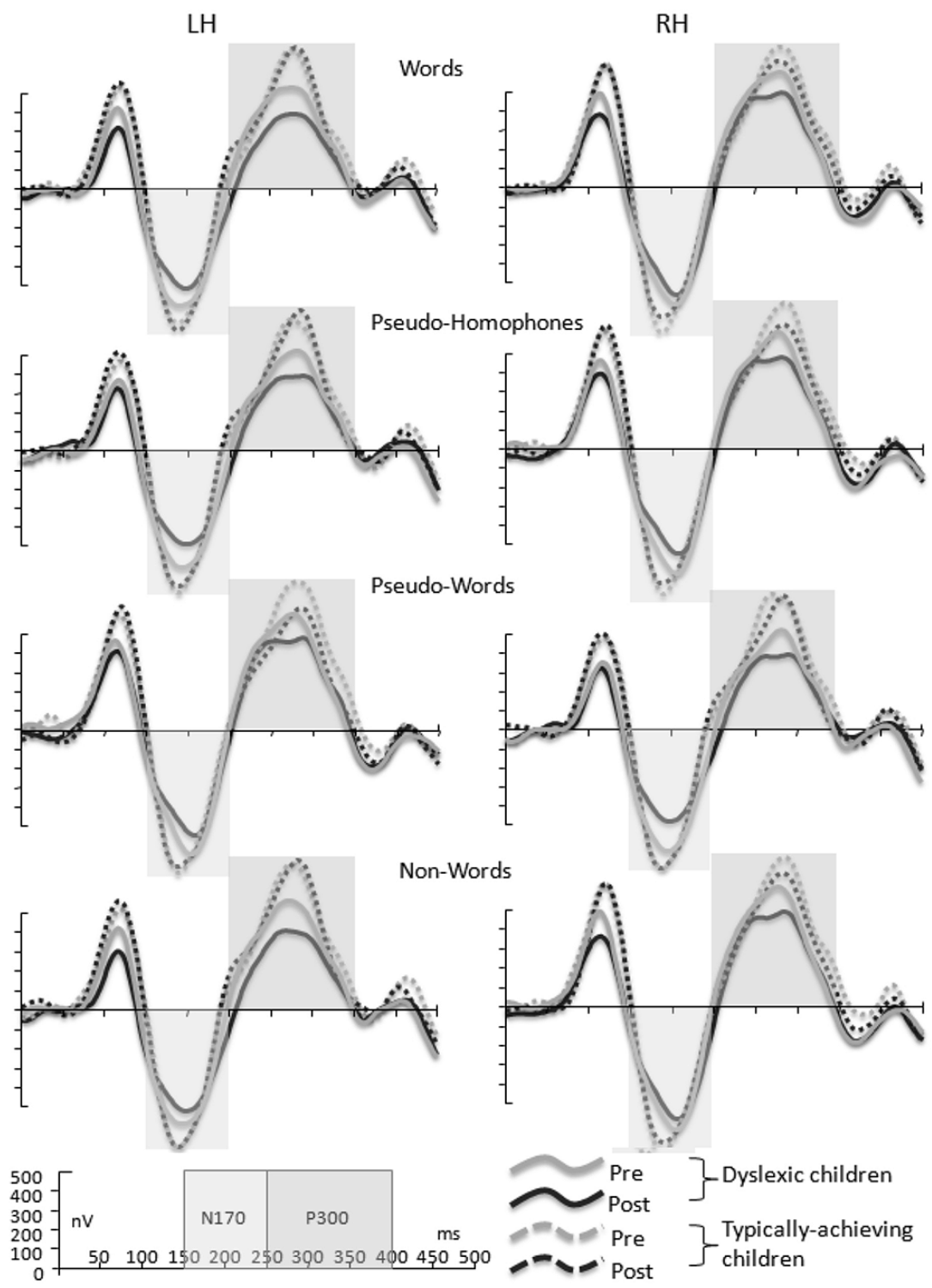

Fig. 1. ERP curves obtained from the linear derivation of $\mathrm{P} 7, \mathrm{PO} 9$ and $\mathrm{O} 1$ for the left hemisphere (LH) and $\mathrm{P} 8, \mathrm{PO} 10$ and $\mathrm{O} 2$ for the right hemisphere (RH) in the different conditions of the visual lexical decision task at session 1 and 2 (pre/post) in both groups of children.

fect is crucial during reading acquisition, it is known that the orthographic lexicon is not stable at the maturational stage [16] corresponding to the children we studied (mean chronological age 10 years).

Secondly, looking at the ERPs results, we observed that words elicited a higher P300 amplitude than other stimuli (non-words and pseudo-words) in both groups. This finding may be interpreted as a typical attentional effect when target occurrence is less frequent than distracters $[34,38]$. In our paradigm, real words only represented $25 \%$ of items. However, this difference only occurred in the left hemisphere, showing a possible supplementary attentional load due to lexical treatment in this hemisphere [14].

We could not demonstrate a main session effect but complex session $\mathrm{x}$ condition $\mathrm{x}$ group interactions were found in behavioral and electrophysiological results (see Table 2). Both groups showed improvement in the task and a decrease of N170 latency and P300 mean amplitude. As the control group did not receive any specific training, this could easily be attributed to procedural learning of the task. Nevertheless, the specificity of these modulations of activity according to the group 
Table 2

Effects distribution observed between first and last session

\begin{tabular}{lcc}
\hline Observed effect & Dyslexic group & Control group \\
\hline Recognition improvement & Words & Pseudo-homophones \\
N170 latency decrease & Pseudo-words & Non-words \\
N170 amplitude decrease & Pseudo-words and pseudo-homophones & $/$ \\
P300 amplitude decrease & Words and Non-words & Pseudo-words and pseudo-homophones \\
\hline
\end{tabular}

and condition suggests a more complex interpretation of these findings.

A relationship between behavioral and electrophysiological changes seems to emerge, showing dissociation between N170, P300 and behavioral changes (see Table 2). In the dyslexic group, P300 amplitude decreased for non-words and words whereas the latter yielded performance improvement. In the control group, the same effect was observed for pseudo-words. At the same time, the opposite pattern occurred for the N170 latency, which was shortened for pseudo-words and pseudo-homophones in the dyslexic group (the latter result being associated with a decrease of the peak mean amplitude) and for words in the typically achieving children without any correlates on behavioral results. These results raise two questions. First, why would electrophysiological change be related with behavioral improvement only for the P300 component? Second, why did we observe an opposite condition effect depending to the group?

In this study, we used a lexical decision task in an oddball paradigm in order to investigate both orthographic and attentional processing. It appeared that the task required heavy attentional load due to short presentation time. As shown in Table 1, an important variance in the performance of the two groups was observed. Taking this into account and the variance in electrophysiological data, we might be facing a basic problem of statistical power that could not allow showing more effects. Therefore, due to the attentional demand required by the task, $\mathrm{P} 300$ effects might be more robust than N170 ones. It would be of interest to further investigate our hypothesis on the N170 component on a classic lexical decision task with a greater group of subjects. Moreover, we argue that a possible behavioral improvement in this specific task would more rely on attention than orthographic processing skills. In their remediation study, Santos et al. [43] put forward ERP change in the P300 component after an audiovisual training program in dyslexia in a pitch incongruity perception task. They argue that the training provides better skills in detection tasks. Furthermore, other learning studies have shown a great sensitivity of the P300 component to cognitive changes occurring after training [20,31,39].
Moving to our second question, one may wonder whether the changes observed in the two groups, with opposite effects of conditions, rely on the same processes in both groups. We argue that the mechanisms involved are different in the dyslexic compared to typically achieving children. In the control group, it may be suggested that procedural learning accounted for an improvement of performance on pseudo-words; this processing facilitation might account for P300 amplitude decrease as a result of decreased attentional load. This effect would only appear for the pseudo-words as performance on identification of both non-words and words in this group was already high at session 1 (resp. $82 \%$ and $75 \%$ ) while subjects were less accurate for pseudo-words and pseudo-homophones (resp. 65\% and $56 \%$ ). Concerning dyslexic children, if their improvement had been only related to procedural learning, we would have expected performance increase to be independent of condition; and these subjects were deficient in all conditions compared to their peers. Instead, the training received might be at least partly responsible for the observed difference between conditions. The training was built, first, to improve visual attention and phonemic awareness and, second, to enhance the lexical route for reading, which permits good literacy skills in proficient pupils [13]. From orthographic representation to phonological coding, the children in the present study were taught how to implicitly use this route. According to the visual attention span deficit theory [55], word recognition requires a higher attentional level in dyslexic children, especially when they are confronted with long orthographic sequences [4]. So the decrease of P300 amplitude in the word condition may result from a reduced allocation of attention resources to these stimuli because of a better word identification (a specific improvement in reading process).

\section{Conclusion}

In this study, we have shown that cortical activity in dyslexic children in a visual word recognition task might be modulated by training. 
However, only P300 modifications were related to behavioral improvement, both in dyslexic and in control subjects. Considering the well-known implication of P300 in attentional processes, our results reflect the strong link between reading skill improvement after remediation and visuo-attentional process maturation.

\section{Acknowledgement}

We would like to thank Margot Taylor, Magali Batty, Marianne Latinus, Chloé de Boysson, Maria Trabanino, Stéphanie Iannuzzi, Evelyne Calvet, and Isabelle Barry for their help in the preparation and execution of this experiment. In its first phase, this research was supported by the INSERM program "PROGRES" and by a grant from the Clinical Research Hospital Program from the French Ministry of Health (PHRC 2002, University Hospital of Toulouse $\mathrm{N}^{\circ}$ 0203208) and then by the "ARS 2000" program of the French Foundation for Medical research ("Fondation Recherche Médicale").

\section{References}

[1] A.W. Alexander and A.M. Slinger-Constant, Current status of treatments for dyslexia: critical review, J Child Neurol 19(10) (2004), 744-758.

[2] A. Beaton, Dyslexia, reading and the brain: a sourcebook of psychological and biological research, 2004, Hove: Psychology. viii, 348.

[3] S. Bentin, Y. Mouchetant-Rostaing, M.H. Giard, J.F. Echallier and J. Pernier, ERP manifestations of processing printed words at different psycholinguistic levels: time course and scalp distribution, J Cogn Neurosci 11(3) (1999), 235-260.

[4] M.L. Bosse, M.J. Tainturier and S. Valdois, Developmental dyslexia: The visual attention span deficit hypothesis, Cognition 104(2) (2007), 198-230.

[5] R. Brickenkamp, Test d'attention concentrée: d2, 1998, Paris: Les Editions du Centre de Psychologie Appliquée.

[6] C. Chevrie-Muller, A.M. Simon and S. Fournier, Batterie Langage oral et écrit. Mémoire. Attention. (L2MA), 1997, Paris: Editions du Centre de Psychologie Appliquée.

[7] M. Coltheart, K. Rastle, C. Perry, R. Langdon and J. Ziegler, DRC: a dual route cascaded model of visual word recognition and reading aloud, Psychol Rev 108(1) (2001), 204-256.

[8] P. Cornelissen, A. Tarkiainen, P. Helenius and R. Salmelin, Cortical effects of shifting letter position in letter strings of varying length, J Cogn Neurosci 15(5) (2003), 731-746.

[9] L. Danon-Boileau and D. Barbier, Play-On: Un logiciel d'entraînement à la lecture, 2002, Audivi-Média: Paris.

[10] J.J. Deltour, Test de closure grammaticale (révisé). (TCG-R), 1998, Parie: EAP.

[11] J.F. Démonet, M.J. Taylor and Y. Chaix, Developmental dyslexia, Lancet 363(9419) (2004), 1451-1460.

[12] C.C. Duncan, J.M. Rumsey, S.M. Wilkniss, M.B. Denckla, S.D. Hamburger and M. Odou-Potkin, Developmental dyslexia and attention dysfunction in adults: brain potential indices of information processing, Psychophysiology 31(4) (1994), $386-401$.
[13] A.W. Ellis, Reading, writing and dyslexia: a cognitive analysis, 1984, London: Lawrence Erlbaum Associates. 147.

[14] A.W. Ellis, R. Ferreira, P. Cathles-Hagan, K. Holt, L. Jarvis and L. Barca, Word learning and the cerebral hemispheres: from serial to parallel processing of written words, Philos Trans R Soc Lond B Biol Sci 364(1536) (2009), 3675-3696.

[15] A. Facoetti, P. Paganoni, M. Turatto, V. Marzola and G.G. Mascetti, Visual-spatial attention in developmental dyslexia, Cortex 36(1) (2000), 109-123.

[16] M. Fayol and J.-P. Jaffré, Orthographier. 1reéd. ed. Apprendre. 2008, Paris: Presses universitaires de France. 232.

[17] M. Habib, R. Espesser, V. Rey, K. Giraud, P. Bruas and C. Gres, Training dyslexics with acoustically modified speech: evidence of improved phonological performance, Brain \& Cognition 40 (1999), 143-146.

[18] M. Habib, V. Rey, V. Daffaure, R. Camps, R. Espesser, B. JolyPottuz and J.F. Demonet, Phonological training in children with dyslexia using temporally modified speech: a three-step pilot investigation, Int J Lang Commun Disord 37(3) (2002), 289-308.

[19] P. Helenius, A. Tarkiainen, P. Cornelissen, P.C. Hansen and R. Salmelin, Dissociation of normal feature analysis and deficient processing of letter-strings in dyslexic adults, Cereb Cortex 9(5) (1999), 476-483.

[20] A.P. Key, D.L. Molfese and E.D. Ratajczak, ERP indicators of learning in adults, Dev Neuropsychol 29(2) (2006), 379-395.

[21] A.F. Kramer and D.L. Strayer, Assessing the development of automatic processing: an application of dual-task and eventrelated brain potential methodologies, Biol Psychol 26(1-3) (1988), 231-267.

[22] S. Kuriki, F. Takeuchi and Y. Hirata, Neural processing of words in the human extrastriate visual cortex, Brain Res Cogn Brain Res 6(3) (1998), 193-203.

[23] P. Lecocq, L'É.CO.S.SE: une épreuve de compréhension syntaxico- sémantique. Psychologie cognitive. 1996, Villeneuve d'Ascq (France): Presses universitaires du Septentrion.

[24] P. Lefavrais, Test de l'Alouette : Manuel. 1967, Paris: Les Editions du Centre de Psychologie Appliquée.

[25] M.W. Lovett, M.J. Ransby, N. Hardwick, M.S. Johns and S.A. Donaldson, Can dyslexia be treated? Treatment-specific and generalized treatment effects in dyslexic children's response to remediation, Brain Lang 37(1) (1989), 90-121.

[26] A. Magnan and J. Ecalle, Audio-visual training in children with reading disabilities, Computers \& Education 46(4) (2006), 407-425.

[27] A. Magnan, J. Ecalle, E. Veuillet and L. Collet, The effects of an audio-visual training program in dyslexic children, Dyslexia 10(2) (2004), 131-140.

[28] C.D. Martin, T. Nazir, G. Thierry, Y. Paulignan and J.F. Demonet, Perceptual and lexical effects in letter identification: an event-related potential study of the word superiority effect, Brain Res 1098(1) (2006), 153-160.

[29] U. Maurer, S. Brem, K. Bucher, F. Kranz, R. Benz, H.C. Steinhausen and D. Brandeis, Impaired tuning of a fast occipitotemporal response for print in dyslexic children learning to read, Brain 130(Pt 12) (2007), 3200-3210.

[30] A.C. Nobre, T. Allison and G. McCarthy, Word recognition in the human inferior temporal lobe, Nature 372(6503) (1994), 260-263.

[31] K.A. Paller, M. Kutas and A.R. Mayes, Neural correlates of encoding in an incidental learning paradigm, Electroencephalogr Clin Neurophysiol 67(4) (1987), 360-371. 
[32] K. Pammer, P.C. Hansen, M.L. Kringelbach, I. Holliday, G. Barnes, A. Hillebrand, K.D. Singh and P.L. Cornelissen, Visual word recognition: the first half second, Neuroimage 22(4) (2004), 1819-1825.

[33] B.F. Pennington, G.C. Van Orden, S.D. Smith, P.A. Green and M.M. Haith, Phonological processing skills and deficits in adult dyslexics, Child Dev 61(6) (1990), 1753-1778.

[34] T.W. Picton, The P300 wave of the human event-related potential, J Clin Neurophysiol 9(4) (1992), 456-479.

[35] T.W. Picton, S. Bentin, P. Berg, E. Donchin, S.A. Hillyard, R. Johnson, Jr., G.A. Miller, W. Ritter, D.S. Ruchkin, M.D. Rugg and M.J. Taylor, Guidelines for using human eventrelated potentials to study cognition: recording standards and publication criteria, Psychophysiology 37(2) (2000), 127-152.

[36] A.M. Proverbio, B. Cok and A. Zani, Electrophysiological measures of language processing in bilinguals, J Cogn Neurosci 14(7) (2002), 994-1017.

[37] A.M. Proverbio and A. Zani, Time course of brain activation during graphemic/phonologic processing in reading: an ERP study, Brain Lang 87(3) (2003), 412-420.

[38] W. Ritter and H.G. Vaughan, Jr., Averaged evoked responses in vigilance and discrimination: a reassessment, Science 164(877) (1969), 326-328.

[39] M. Rose, R. Verleger and E. Wascher, ERP correlates of associative learning, Psychophysiology 38(3) (2001), 440-450.

[40] A.P. Rudell and J. Hua, The recognition potential, word difficulty, and individual reading ability: on using event-related potentials to study perception, J Exp Psychol Hum Percept Perform 23(4) (1997), 1170-1195.

[41] R. Salmelin, P. Helenius and E. Service, Neurophysiology of fluent and impaired reading: a magnetoencephalographic approach, J Clin Neurophysiol 17(2) (2000), 163-174.

[42] R. Salmelin, E. Service, P. Kiesila, K. Uutela and O. Salonen, Impaired visual word processing in dyslexia revealed with magnetoencephalography, Ann Neurol 40(2) (1996), 157-162.

[43] A. Santos, B. Joly-Pottuz, S. Moreno, M. Habib and M. Besson, Behavioural and event-related potentials evidence for pitch discrimination deficits in dyslexic children: improvement after intensive phonic intervention, Neuropsychologia 45(5) (2007), 1080-1090.

[44] P. Sauseng, J. Bergmann and H. Wimmer, When does the brain register deviances from standard word spellings?-An ERP study, Brain Res Cogn Brain Res 20(3) (2004), 529-532.

[45] S.C. Sereno, C.C. Brewer and P.J. O’Donnell, Context effects in word recognition: evidence for early interactive processing, Psychol Sci 14(4) (2003), 328-333.

[46] S.C. Sereno, K. Rayner and M.I. Posner, Establishing a timeline of word recognition: evidence from eye movements and event-related potentials, Neuroreport 9(10) (1998), 21952200.

[47] M.J. Snowling, Dyslexia. 2ed. 2000, Oxford: Blackwell.

[48] M.J. Snowling, From language to reading and dyslexia, Dyslexia 7(1) (2001), 37-46.

[49] M.J. Snowling, N. Goulandris, M. Bowlby and P. Howell, Segmentation and speech perception in relation to reading skill: a developmental analysis, J Exp Child Psychol 41(3) (1986), 489-507.

[50] K.E. Stanovich and L.S. Siegel, The phenotypic performance profile of reading-disabled children: a regression based test of the phonological core variable-difference model, Journal of Educational Psychology 86 (1994), 24-53.

[51] A. Tarkiainen, P. Helenius, P.C. Hansen, P.L. Cornelissen and R. Salmelin, Dynamics of letter string perception in the human occipitotemporal cortex, Brain 122(Pt 11) (1999), 2119-2132.

[52] N.A. Taroyan and R.I. Nicolson, Reading words and pseudowords in dyslexia: ERP and behavioural tests in Englishspeaking adolescents, Int J Psychophysiol 74(3) (2009), 199208.

[53] M.J. Taylor, The role of event-related potentials in the study of normal and abnormal cognitive development, in: Handbook of neuropsychology, F. Boller and J. Grafman, eds, Elsevier: Amsterdam; New York, 1995, pp. 187-211.

[54] J.K. Torgesen, A.W. Alexander, R.K. Wagner, C.A. Rashotte, K.K. Voeller and T. Conway, Intensive remedial instruction for children with severe reading disabilities: immediate and longterm outcomes from two instructional approaches, J Learn Disabil 34(1) (2001), 33-58, 78.

[55] S. Valdois, M.L. Bosse and M.J. Tainturier, The cognitive deficits responsible for developmental dyslexia: review of evidence for a selective visual attentional disorder, Dyslexia 10(4) (2004), 339-363.

[56] D. Wechsler, Echelle d'intelligence Wechsler pour enfants, 1996, Paris: Les Editions du Centre de Psychologie Appliquée.

[57] C. Wickens, A. Kramer, L. Vanasse and E. Donchin, Performance of concurrent tasks: a psychophysiological analysis of the reciprocity of information-processing resources, Science 221(4615) (1983), 1080-1082. 


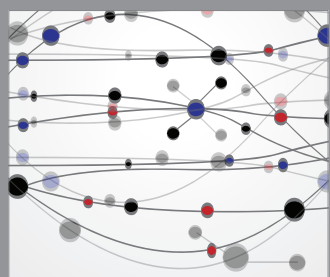

The Scientific World Journal
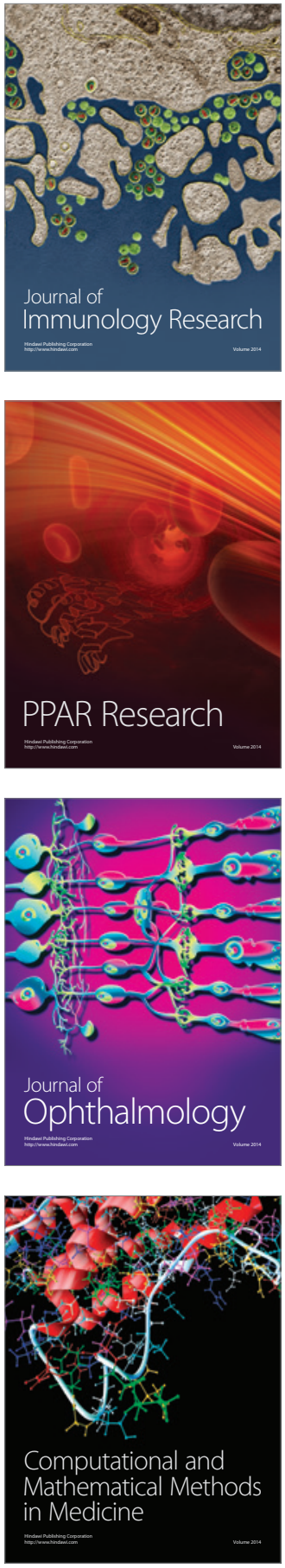

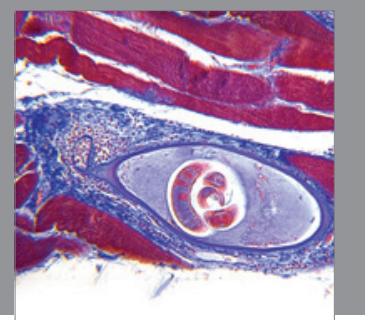

Gastroenterology

Research and Practice
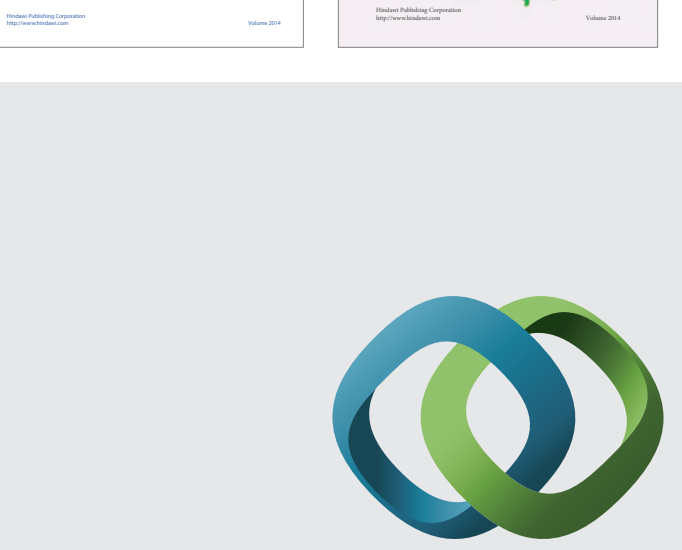

\section{Hindawi}

Submit your manuscripts at

http://www.hindawi.com
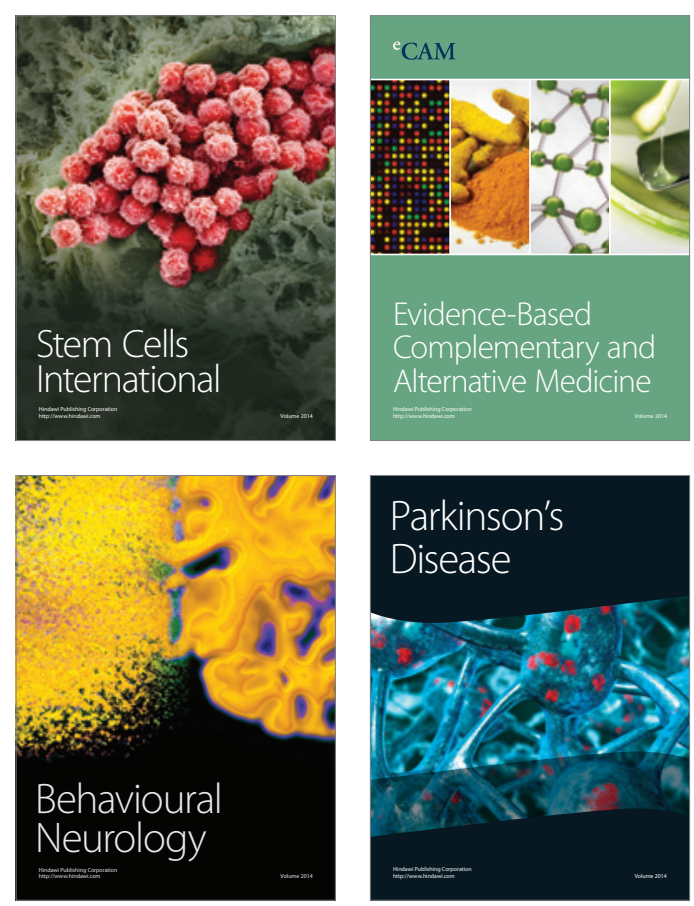

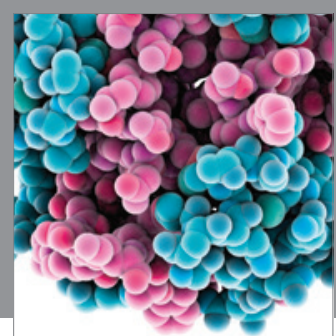

Journal of
Diabetes Research

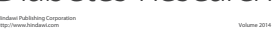

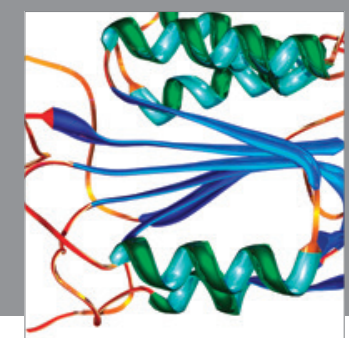

Disease Markers
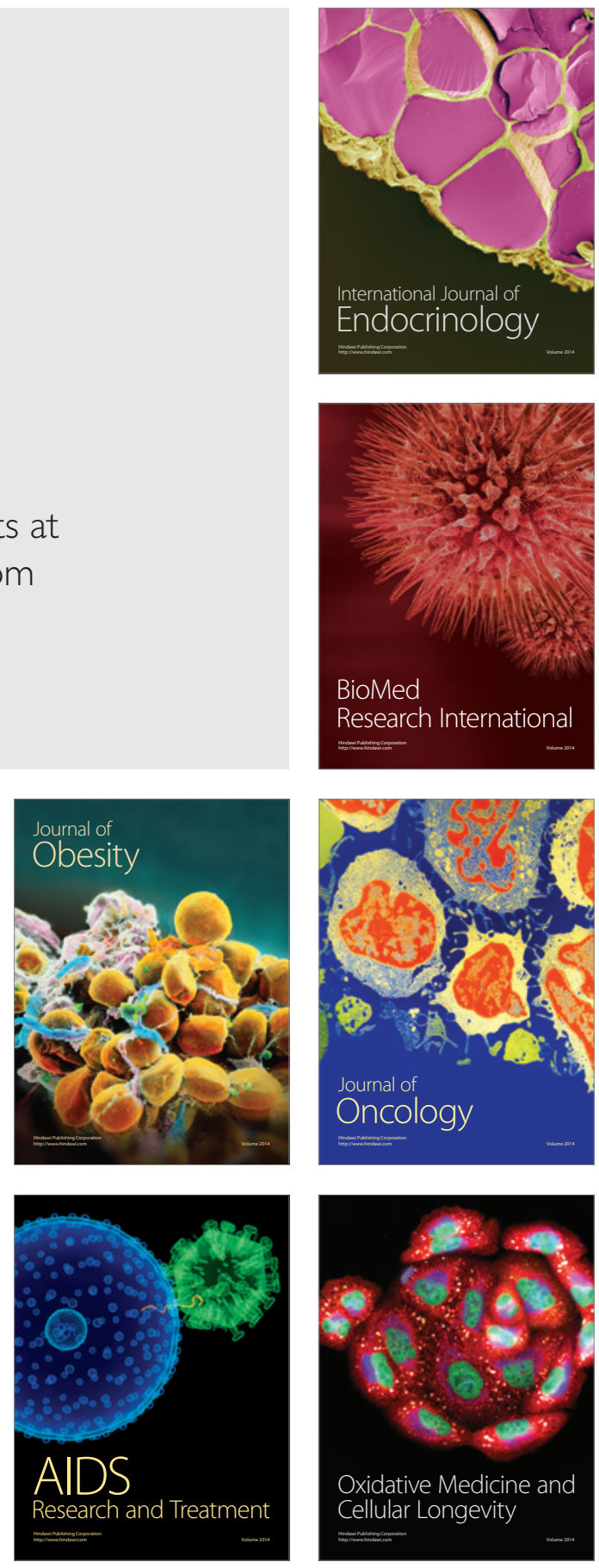